\title{
Effectiveness of Wildlife Underpasses and Fencing to Reduce Wildlife-Vehicle Collisions
}

\author{
MATTHEW F. MCCOLLISTER, ${ }^{1}$ University of Tennessee, Department of Forestry, Wildlife and Fisheries, 274 Ellington Plant Sciences Building, \\ Knoxville, TN 37996, USA \\ FRANK T. VAN MANEN, ${ }^{2}$ United States Geological Survey, Leetown Science Center, University of Tennessee, Department of Forestry, Wildlife and \\ Fisheries, 274 Ellington Plant Sciences Building, Knoxville, TN 37996, USA
}

\begin{abstract}
Transportation planners are increasingly incorporating roadway design features to mitigate impacts of highways on wildlife and to increase driver safety. We used camera and track surveys to evaluate wildlife use before and after construction of 3 wildlife underpasses and associated fencing on a new section of United States Highway 64 in Washington County, North Carolina, USA. We recorded 242 occasions of white-tailed deer (Odocoileus virginianus) use of underpass areas before highway construction began. Following completion of the highway, we collected 2,433 photographs of 9 species with deer representing $93 \%$ of all crossings. Adjusting for differences in number of monitoring days, white-tailed deer use of underpass areas averaged 6.7 times greater after the new highway and underpasses were completed. We recorded 3,614 wildlife crossings of $\geq 20$ species based on track counts, representing most medium and large mammals known to occur in the area and several reptiles and birds. After completion of the highway, we documented wildlife mortality due to vehicle collisions during a 13month period and recorded 128 incidences representing $\geq 24$ species. Within fenced highway segments, mortalities were lowest near underpasses and increased with distance from the underpasses. However, we also documented more mortalities in fenced areas compared with unfenced areas. With greater distance from an underpass, animals with smaller home ranges seemed less likely to reach the underpass and instead attempted to climb over or crawl under fencing. Based on collision reports from adjacent highway sections, the new section of United States Highway 64 experienced approximately 58\% fewer wildlife mortalities (primarily white-tailed deer), suggesting underpasses and fencing reduced the number of deer-vehicle collisions. Continuous fencing between underpasses may further reduce the number of vehicle collisions for deer but additional design features (e.g., buried fencing) should be considered for other wildlife species.
\end{abstract}

KEY WORDS driver safety, fencing, habitat connectivity, transportation infrastructure, wildlife passageways, wildlife-vehicle collisions.

Expanding transportation networks pose a variety of ecological risks of which wildlife-vehicle collisions present a particular challenge for wildlife managers and transportation planners (Forman and Alexander 1998, Forman et al. 2003). For example, high mortality due to vehicle collisions can affect viability of some small populations (e.g., Florida panther [Puma concolor coryi]; Foster and Humphrey 1995). In areas with healthy populations of large ungulates, driver safety also is an important concern. Wildlife-vehicle collisions cause substantial property damage, human injuries, and even human fatalities (Conover et al. 1995, Groot Bruinderink and Hazebroek 1996, Romin and Bissonette 1996). Transportation planners are increasingly incorporating design features to mitigate impacts of highways on wildlife and to increase driver safety. Mirrors, reflectors, and lighting have been used to reduce wildlife-vehicle collisions, but effectiveness of these devices is questionable (Pojar et al. 1975, Reed and Woodward 1981, Groot Bruinderink and Hazebroek 1996, Forman et al. 2003, D’Angelo et al. 2006). The first concerted efforts to incorporate wildlife passageways in the United States (e.g., overpasses, underpasses, culverts, tunnels) began during the 1970s (Evink 1996) but such measures were not routinely considered in transportation planning until recent decades (Cramer and Bissonette 2006).

\footnotetext{
${ }^{1}$ Present address: 2405 Henrietta Road, Birmingham, AL 35223, USA ${ }^{2}$ E-mail:vanmanen@utk.edu
}

In 1992 the North Carolina Department of Transportation (NCDOT) initiated plans to upgrade United States Highway 64 between Raleigh and coastal areas of the Outer Banks from a 2-lane, rural roadway to a 4-lane, divided highway. Included in these plans was a new route for United States Highway 64 in Washington County, North Carolina, USA (Fig. 1). The new 24.1-km route did not follow existing roads and traversed large forested tracts interspersed with agricultural areas, which provided important habitat for American black bears (Ursus americanus) and federally endangered red wolves (Canis rufus; M. D. Jones, North Carolina Wildlife Resources Commission [NCWRC], personal communication). White-tailed deer (Odocoileus virginianus), abundant in the study area, also were considered in the planning process because of known human safety risks associated with deer-vehicle collisions (Conover et al. 1995). Consequently, NCWRC consulted with NCDOT to incorporate 3 wildlife underpasses and fencing in the highway design (Jones et al. 2010; Fig. 1).

Several studies examined effectiveness of passageways or fencing (Falk et al. 1978, Ward 1982, Ludwig and Bremicker 1983, Feldhamer et al. 1986, Clevenger et al. 2001a) and tested different passageway designs (Clevenger and Waltho 2000). Most of these studies focused on large mammals, often one species, but transportation planners are increasingly considering mitigation for larger suites of species (Clevenger and Waltho 2000). Additionally, few researchers obtained wildlife use data before underpasses were constructed. Finally, differences in frequency of 


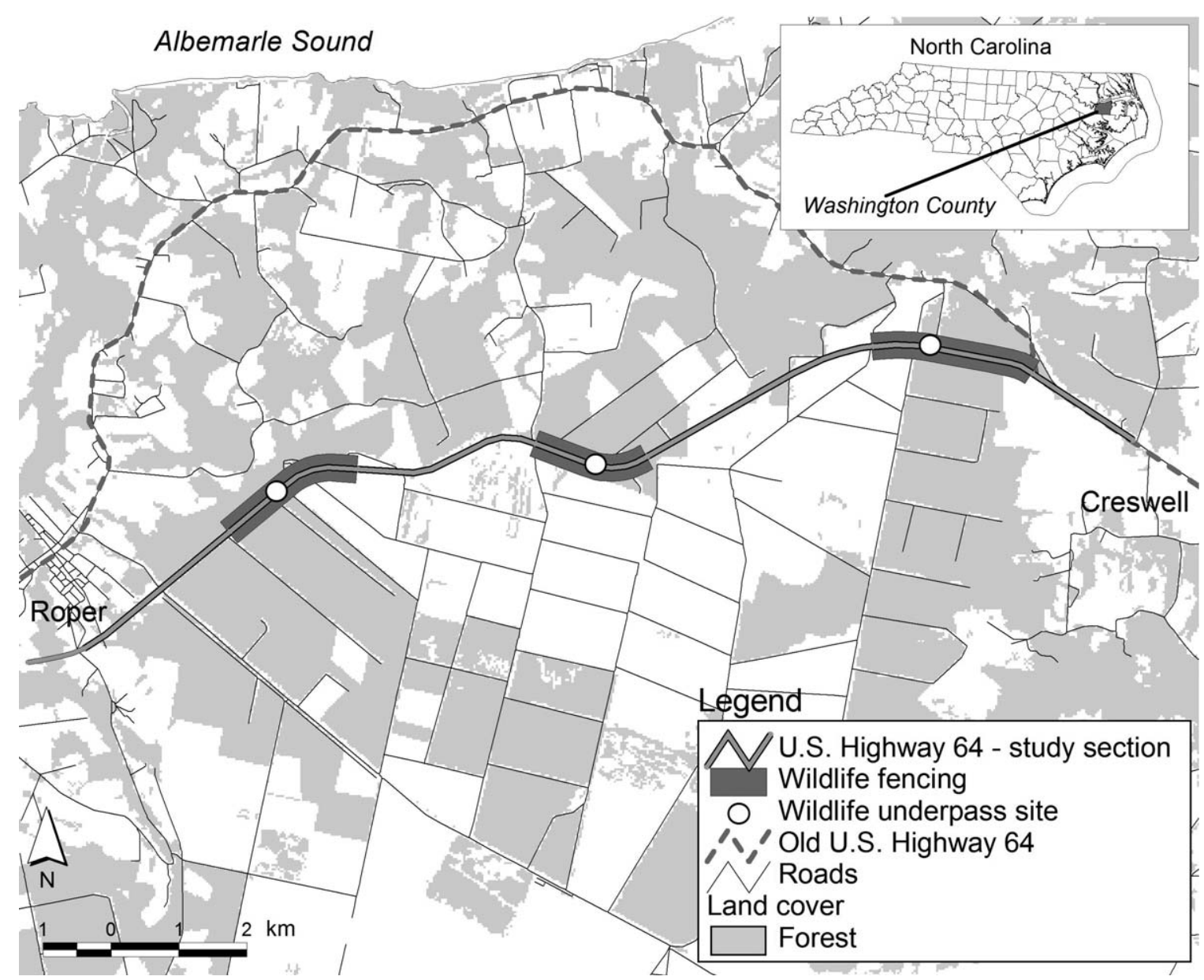

Figure 1. Study section of United States Highway 64 to determine effectiveness of wildlife underpasses and fencing in Washington County, North Carolina, USA, 2000-2007. The new highway included 4 stretches without wildlife underpass and fencing separated by 3 stretches with wildlife underpasses and fencing. Construction of the new highway and 3 wildlife underpasses started in June 2001 and was completed in September 2005.

wildlife mortality along segments with and without underpasses and fencing within a section of highway have not been intensively studied. Our objective was to determine the effectiveness of underpasses and fencing to reduce wildlife-vehicle collisions. We hypothesized that underpasses and fencing would reduce wildlife mortalities due to vehicle collisions by concentrating wildlife crossings of the roadway through safe passageways.

\section{STUDY AREA}

Our 17.3-km highway study section was within a new section of United States Highway 64 between Roper and Creswell (Fig. 1). Land use within the project area was primarily related to forestry (54\%) and agriculture (38\%; wheat, soybeans, corn, cotton, tobacco, peanuts, and turf grass). Forest lands mostly consisted of loblolly pine (Pinus taeda) plantations. Hardwood forests were limited to small woodlots, farms, conservation easements, and natural drainages consisting of various oak species (Quercus spp.), sweetbay (Magnolia virginiana), redbay (Persea borbonia), and blackgum (Nyssa sylvatica). Human development was limited to a few homes scattered among private farms and the towns of Roper and Creswell. Washington County had 13,723 residents in 2000 (12.5 people $/ \mathrm{km}^{2}$; U.S. Census
Bureau 2002). An extensive network of unpaved roads and canals occurred throughout the study area. Unpaved roads typically were gated and remained locked, limiting use to forestry and farm equipment operators, hunters, and landowners.

No highway existed within the project area during the first phase of our study. Construction of the new highway started in June 2001 and was completed in September 2005. The new highway consisted of a 4-lane, divided roadway, crossed a variety of manmade waterways, and had a posted speed limit of $113 \mathrm{~km} / \mathrm{hr}$ (70 miles/hr) for most of its length. To mitigate potential impacts of the highway on wildlife, 3 underpasses were constructed (Fig. 1). Locations of underpasses were determined primarily based on sign surveys and focused on large to medium-sized mammals (Jones et al. 2010). Vertical clearance of all 3 underpasses was approximately $3 \mathrm{~m}$ and length (distance between the 2 entrances of each underpass, including the open span associated with the highway median) was $35 \mathrm{~m}$. The western underpass had the largest width $(47 \mathrm{~m})$ with a large openness factor (ht $\times$ width/length; Reed et al. 1975) of 4.03, and included a 2.5m-wide creek that flooded the underpass on several occasions. The central underpass had a width of $33 \mathrm{~m}$ (openness factor $=2.82$ ) and spanned a 1 -m-wide ditch that 
contained water throughout the year. The eastern underpass had the smallest width $(29 \mathrm{~m}$; openness factor $=2.48)$ and remained dry for most of the year. To ensure visibility between entrances while providing sufficient cover for wildlife, herbicides were applied to each underpass area in autumn. Trees and shrubs were spot-treated as needed to prevent dominance of woody vegetation. All wildlife fences consisted of 3.0-m-high chain-link fencing with a mesh size of $5 \mathrm{~cm}$. On both sides of the highway, fences began $\geq 800 \mathrm{~m}$ from underpasses, parallel with the highway, continued underneath underpasses and connected to fencing on the opposite side. Multiple gates were incorporated in the fencing to gain access to underpasses or to release wildlife that may access the roadway from the edge of fencing. All gates remained closed and locked otherwise. Where fencing crossed ditches, gaps were blocked with barbed wire. Concrete bollards were placed at underpass entrances to prevent access by off-road vehicles.

\section{METHODS}

\section{Surveys}

Before highway construction began, we documented wildlife use of the 3 planned underpass sites (Jul 2000 to Mar-Apr 2001) with actively triggered (infrared beam between transmitter and receiver) camera systems (Kucera and Barrett 1993; Trailmaster, Inc., Lenexa, KS). Clearing of the underpass areas in preparation of construction prevented us from obtaining camera data during a portion of April and the months of May and June. We used 2 camera systems at each of the 3 proposed underpass sites. All 3 sites were densely forested so we placed cameras within the planned underpass area (T. L. Riddick, NCDOT, unpublished data), rather than monitoring the entire width of each planned underpass, to ensure adequate line of sight (parallel to the projected highway trajectory) between transmitter and receiver units. Combined, effective monitoring distance of the cameras was approximately $30 \mathrm{~m}$ at each planned underpass site. We checked camera systems weekly to ensure proper functioning and to collect film.

After highway construction, we repeated camera surveys to document wildlife use of the 3 underpasses (Aug 2006-Jul 2007). We placed camera systems in the center area of each underpass. We monitored the entire width of underpasses using 8 camera systems: 2 for the eastern underpass and 3 each for the central and western underpasses (Fig. 2). Of these 8 systems, 7 had active infrared sensors and 1 had a passive sensor (detection of animals based on changes in heat energy; Swann et al. 2004). We used a passive sensor to monitor a small span of the western underpass (approx. $8 \mathrm{~m}$ ), whereas we used active sensors to monitor larger distances. We checked all camera systems and collected film twice/ week (every Monday and Thursday). To ensure detection of all medium to large animals, we set the height of sensors at approximately $30 \mathrm{~cm}$. To reduce the probability of doublecounting, we used a date and time stamp on each photo and programmed a camera reset time of 2 minutes before a new photo could be taken. Camera systems recorded an event when the infrared beam was intercepted for $>0.25$ seconds.

Concurrent with camera surveys, we conducted track surveys (Wemmer et al. 1996) twice per week using a 2.5$\mathrm{m}$-wide track pad of bare earth that spanned the width of each underpass (Fig. 2). We identified to species each set of tracks that crossed the track pad and recorded it as a crossing event. We raked the track pad after each survey.

We surveyed our highway study section for 13 months (Jul 2006 through Jul 2007) to record locations of wildlife mortalities due to vehicle collisions. We conducted surveys twice per week (every Monday and Thursday). We conducted surveys along east- and west-bound lanes, starting at the town of Roper and ending at the junction of United States Highway 64 and North Carolina Highway 94, northwest of Creswell (17.3 km; Fig. 1). We recorded species, date, and Global Positioning System coordinates of each animal carcass. We removed animal carcasses from the highway to prevent double counting.

\section{Analysis}

Because monitoring durations for the 2 study phases were not equal, we used the number of camera records/ monitoring day for comparison and calculated the ratio of that statistic for pre- and postconstruction phases. Camera monitoring distances for the western underpass were different before $(30 \mathrm{~m})$ and after $(47 \mathrm{~m})$ highway construction so we applied a correction factor of 0.64 (30/ 47) to that ratio.

Our highway study section consisted of 3 stretches with underpasses and fencing and 4 stretches without such mitigation measures. To account for fine-scaled changes in habitat along this section of highway (e.g., agriculture, forest-agriculture edges, forest) that may influence mortality frequencies, we further divided each of these 7 stretches of highway into 8 equal segments $(n=56$ total segments; Fig. 3). Using a mixed-model analysis of variance (PROC MIXED; SAS Institute, Inc. 2005), we compared the frequency of wildlife mortalities for segments of the new highway at 1) the 3 underpasses (fenced areas within approx. $300 \mathrm{~m}$ from underpass entrances), 2) fenced areas $>300 \mathrm{~m}$ from underpasses, and 3) areas without wildlife fencing. Length of highway segments varied among the 7 stretches of highway, so we used segment length as a covariate. Because locations of the 3 underpasses were chosen based on high frequency of mammal crossings in those areas before highway construction began (Jones et al. 2010) and because local habitat characteristics may influence where animals cross highways, we examined 3 habitat covariates. We used variables to reflect habitat use of the broad range of animals that occurred in the area. We chose percent forest cover within $250 \mathrm{~m}$ of the highway because it represented the primary division of land use within the study area. We used a small area for this measurement because we assumed that habitat adjacent to the highway would have the greatest influence on animals crossing the roadway. Similarly, we created a class variable to indicate presence or absence of forest cover on both sides of the highway and a
1724

The Journal of Wildlife Management wild-74-08-24.3d $\quad$ 17/9/10 $\quad 17: 42: 19$
The Journal of Wildlife Management • 74(8)

1724
Cust \# 2009-535R 


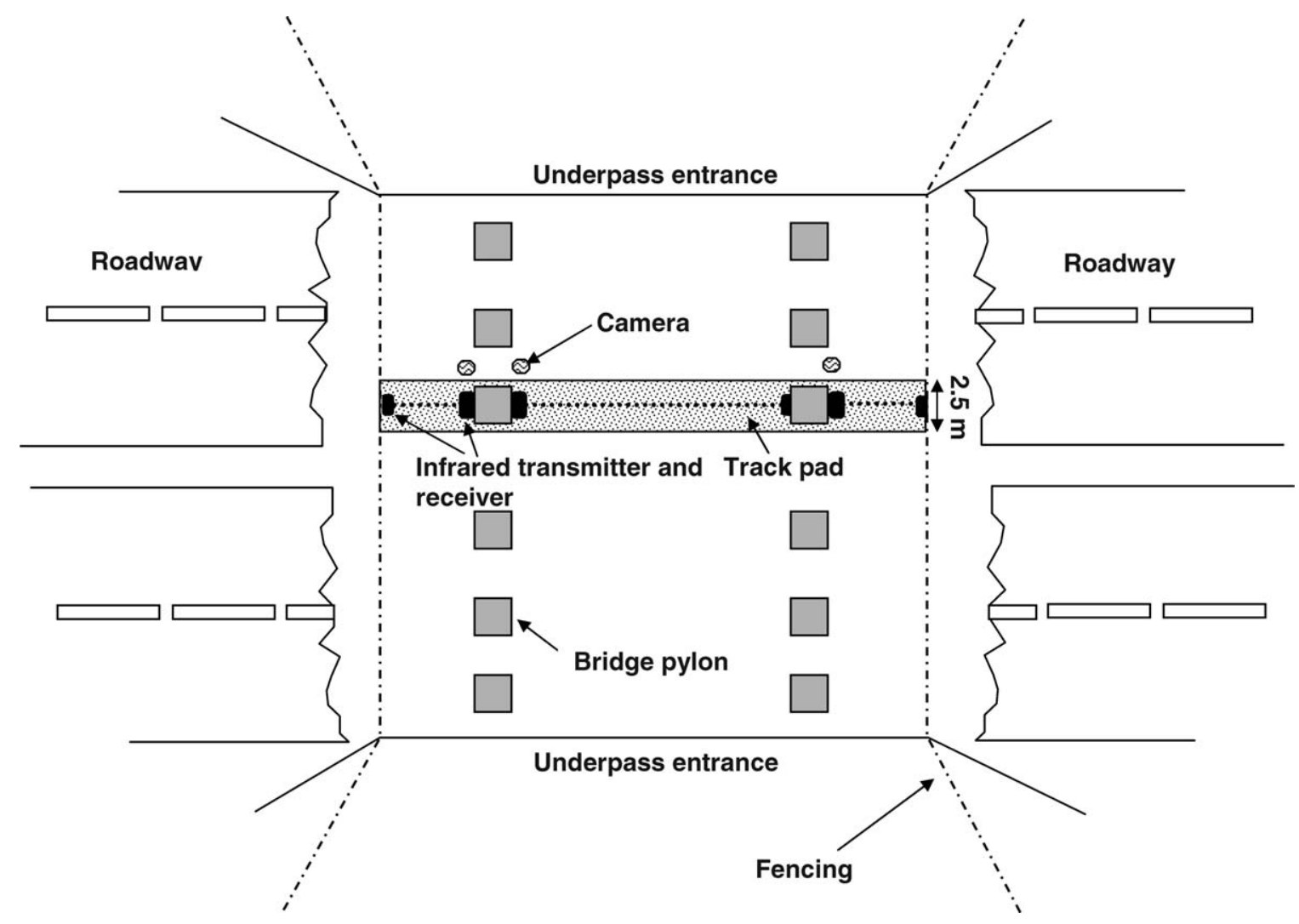

Figure 2. Schematic view of camera systems and track-survey pads used to monitor wildlife use of 3 underpasses along a new section of United States Highway 64, Washington County, North Carolina, USA, 2006-2007. Each camera covered the area between the infrared transmitter and receiver to which it was linked. The infrared beam between each transmitter and receiver pair followed the center of the track-pad survey area.

class variable to indicate presence or absence of a distinct forest-agriculture edge.

We conducted separate analyses for mammals and reptiles and only included species that could not fit through the 5$\mathrm{cm}$ mesh size of fencing. Within fenced segments of the highway, we also tested whether distance from the nearest underpass was associated with frequency of wildlife mortality. We used the Shapiro-Wilk test to verify the normality assumption and Levene's F-statistic to test the assumption of equal variances.

\section{RESULTS}

Remote cameras recorded 242 photographs of white-tailed deer at proposed underpass sites before highway construction began and 2,433 photographs of 9 wildlife species, excluding domestic dogs and cats, using underpasses after the highway was completed (Table 1). White-tailed deer was the only species we recorded before highway construction started; the number of observations of white-tailed deer/monitoring day were 5.9 to $7.9(\bar{x}=6.7, \mathrm{SD}=1.0)$ times greater after underpasses were completed (Table 1). Because we could not collect data during a portion of April and the months of May and June prior to construction, we considered if this could have biased the estimate. We examined monthly variation in the frequency of white-tailed deer crossings using postconstruction data, which represented a complete calendar year. Although the frequency of deer crossings in October ( $\bar{x}=131.7 /$ underpass $)$ was greater than other months $(\bar{x}=56.5 /$ underpass, $\mathrm{SD}=18.7) \mathrm{we}$ observed no overall difference among months $\left(F_{11,24}=\right.$ $1.03, P=0.452)$. Therefore, the lack of spring data prior to construction likely did not bias our findings. Track-count surveys indicated 3,614 animal crossings of $\geq 20$ species (Table 2). Track counts and camera surveys indicated black bears, one of the target species for safe passage, used underpasses on 17 occasions. White-tailed deer used underpasses substantially more than other species (93\% and $88 \%$ of camera and track records, respectively). Ratios of deer observations among the 3 underpasses were similar for camera and track surveys (cameras $=0.48: 1.0: 0.32$; track counts $=0.60: 1 \cdot 0: 0.39$ ) for the west, central, and east underpasses, respectively, but overall counts were lower for camera surveys. Track counts may have been overestimated due to deer movements within underpass areas. Therefore, we used camera counts as a conservative estimate of the number of underpass crossings.

We recorded 128 animal mortalities from vehicle collisions representing $\geq 12$ amphibian and reptile species and 12 mammal species (Table 3). Several of the white-tailed deer mortalities occurred as a result of deer attempting to cross the highway where fencing ended (4 of 7 mortalities occurred $<280 \mathrm{~m}$ from fencing edge). The 2 black bear mortalities occurred in May 2007 and included a subadult male killed within $200 \mathrm{~m}$ of the eastern wildlife underpass and a yearling male killed in the unfenced section between the central and eastern underpass sites. 


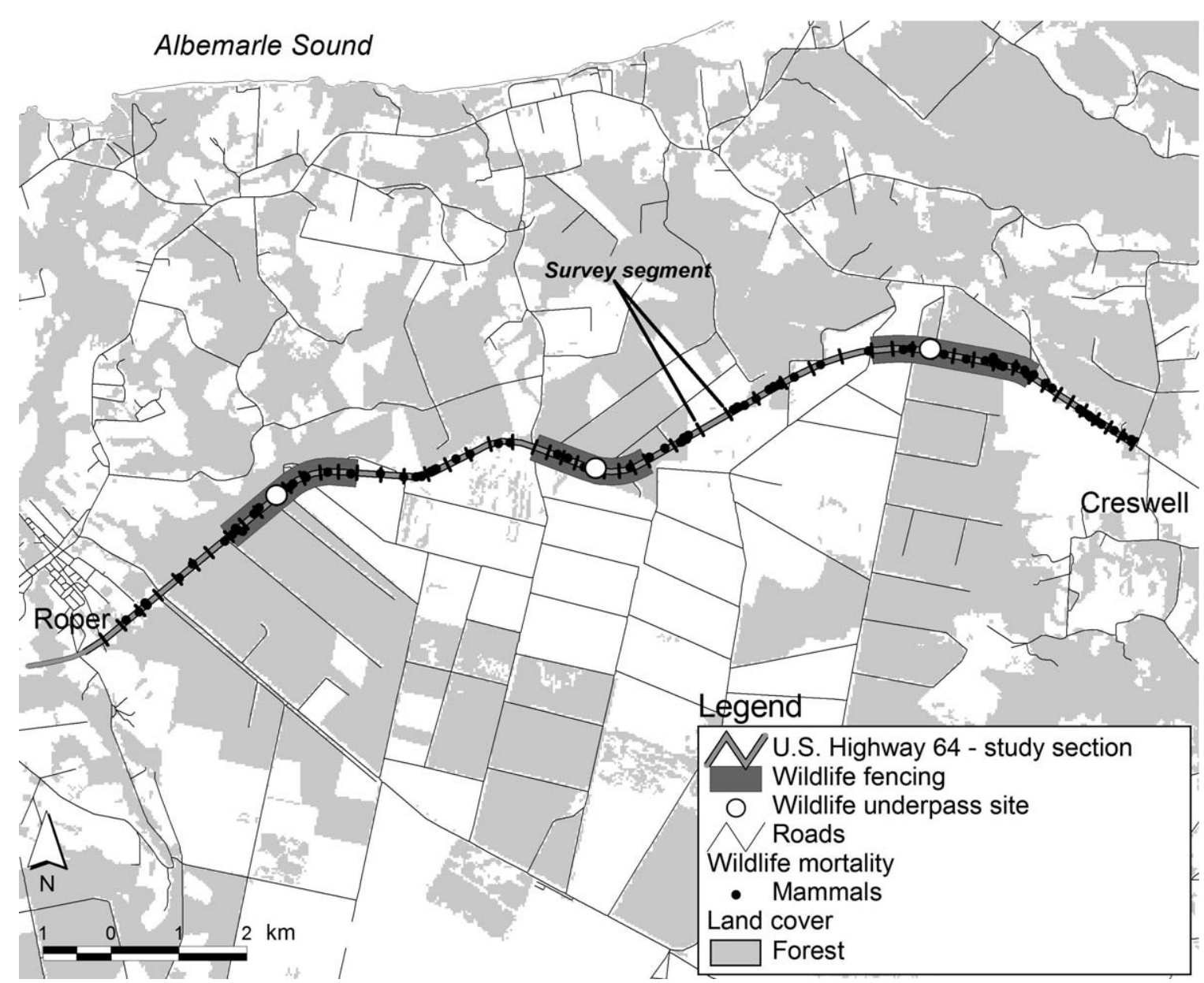

Figure 3. Mammal mortality locations due to vehicle collisions within the study section of United States Highway 64, Washington County, North Carolina, USA, July 2006-July 2007. We divided the study section into 56 survey segments (demarcated by lines perpendicular to the highway) for statistical analysis of mammal mortality frequencies within survey segments that were near an underpass (fenced areas within approx. $300 \mathrm{~m}$ from underpass entrances), fenced (fenced areas $>300 \mathrm{~m}$ from underpasses), or unfenced.

Table 1. Wildlife species identified with remote cameras within 3 wildlife underpasses of United States Highway 64, Washington County, North Carolina, USA, July 2000 to March-April 2001 (preconstruction phase) and August 2006-July 2007 (postconstruction phase).

\begin{tabular}{|c|c|c|c|}
\hline \multirow[b]{2}{*}{ Species } & \multicolumn{3}{|c|}{ Frequency } \\
\hline & West underpass & Central underpass & East underpass \\
\hline \multicolumn{4}{|l|}{ Preconstruction phase } \\
\hline White-tailed deer & 47 & 152 & 43 \\
\hline Total white-tailed deer observations/monitoring day & 0.18 & 0.54 & 0.14 \\
\hline \multicolumn{4}{|l|}{ Postconstruction phase } \\
\hline White-tailed deer & 605 & 1,251 & 402 \\
\hline Observations/monitoring day & 1.66 & 3.43 & 1.10 \\
\hline Raccoon & 95 & 28 & 2 \\
\hline American black bear & 7 & 2 & 6 \\
\hline Bobcat & 10 & 1 & \\
\hline Gray fox (Urocyon cinereoargenteus) & 1 & 7 & \\
\hline Virginia opossum & 3 & 3 & \\
\hline Sylvilagus spp. & 1 & 1 & \\
\hline Canis spp. & 2 & & \\
\hline Great blue heron (Ardea herodias) & 6 & & \\
\hline Total observations/monitoring day & 2.00 & 3.54 & 1.12 \\
\hline Ratio (white-tailed deer) ${ }^{a}$ & 5.9 & 6.4 & 7.9 \\
\hline
\end{tabular}

${ }^{\mathrm{a}}$ Observations/monitoring day for postconstruction phase divided by observations/monitoring day for preconstruction phase for white-tailed deer only. Monitoring distance was approximately $30 \mathrm{~m}$ for all underpass and period combinations; we adjusted the ratio for western underpass for greater monitoring distance during the postconstruction phase $(47 \mathrm{~m})$.

1726

The Journal of Wildlife Management wild-74-08-24.3d 17/9/10 17:42:25
The Journal of Wildlife Management $• 74(8)$
Cust \# 2009-535R 
Table 2. Frequency of wildlife crossings based on track surveys inside 3 wildlife underpasses of United States Highway 64, Washington County, North Carolina, USA, August 2006-July 2007.

\begin{tabular}{|c|c|c|c|}
\hline \multirow[b]{2}{*}{ Species } & \multicolumn{3}{|c|}{ Frequency } \\
\hline & West underpass & Central underpass & East underpass \\
\hline White-tailed deer & 958 & 1,604 & 621 \\
\hline Raccoon & 115 & 79 & 39 \\
\hline Virginia opossum & 13 & 14 & 3 \\
\hline Canis spp. & 12 & 8 & 1 \\
\hline Fox (Vulpes vulpes and Urocyon cinereoargenteus) & 13 & 4 & 5 \\
\hline Sylvilagus spp. & 5 & 9 & \\
\hline Muskrat (Ondatra zibethicus) & 10 & 3 & \\
\hline Bobcat & 8 & 1 & 4 \\
\hline American black bear & 6 & & 6 \\
\hline American mink (Neovison vison) & 1 & 2 & 1 \\
\hline Nutria (Myocastor coypus) & 3 & & \\
\hline Unidentified mole & 2 & & \\
\hline Beaver (Castor canadensis) & & & 1 \\
\hline Wild boar (Sus scrofa) & & 1 & \\
\hline Unidentified snake & 26 & 20 & 6 \\
\hline Unidentified turtle & 2 & 1 & 1 \\
\hline Wild turkey (Meleagris gallopavo) & 1 & & 1 \\
\hline Great blue heron & 1 & 1 & \\
\hline Unidentified bird & 1 & 1 & \\
\hline Total & 1,177 & 1,748 & 689 \\
\hline
\end{tabular}

Table 3. Frequency of wildlife mortalities due to vehicle collisions/kilometer of roadway (mortality rate) for segments of United States Highway 64 with or without wildlife underpasses and fencing, Washington County, North Carolina, USA, July 2006-July 2007.

\begin{tabular}{|c|c|c|c|c|}
\hline \multirow[b]{2}{*}{ Species } & \multicolumn{2}{|c|}{ Underpasses and fencing ${ }^{a}$} & \multicolumn{2}{|c|}{ No underpasses and fencing } \\
\hline & Mortality rate $(n / \mathrm{km})$ & $n$ & Mortality rate $(n / \mathrm{km})$ & $n$ \\
\hline \multicolumn{5}{|l|}{ Amphibians and reptiles } \\
\hline Snapping turtle (Chelydra serpentina) & 0.16 & 1 & 0.83 & 9 \\
\hline Painted turtle (Chrysemys picta) & & & 0.46 & 5 \\
\hline American bullfrog (Lithobates catesbeianus) ${ }^{c}$ & 0.31 & 2 & 0.28 & 3 \\
\hline Eastern box turtle (Terrapene carolina) & 0.31 & 2 & 0.18 & 2 \\
\hline Racer $(\text { Coluber constrictor })^{\mathrm{c}}$ & 0.16 & 1 & 0.18 & 2 \\
\hline Rat snake (Elaphe obsoleta $)^{\mathrm{c}}$ & 0.16 & 1 & 0.18 & 2 \\
\hline Spotted turtle & 0.16 & 1 & 0.09 & 1 \\
\hline Eastern mud turtle (Kinosternon subrubrum) & & & 0.18 & 2 \\
\hline River cooter (Pseudemys concinna) & 0.16 & 1 & 0.09 & 1 \\
\hline Red-bellied snake (Storeria occipitomaculata) ${ }^{\mathrm{c}}$ & & & 0.18 & 2 \\
\hline Plain-bellied water snake $(\text { Nerodia erythrogaster })^{\mathrm{c}}$ & 0.16 & 1 & & \\
\hline Bufo spp..$^{\mathrm{c}}$ & & & 0.09 & 1 \\
\hline Subtotal $(n)$ & 1.57 & 10 & 2.76 & 30 \\
\hline \multicolumn{5}{|l|}{ Mammals } \\
\hline Virginia opossum & 2.82 & 18 & 2.39 & 26 \\
\hline Raccoon & 0.94 & 6 & 1.20 & 13 \\
\hline White-tailed deer & 0.63 & 4 & 0.28 & 3 \\
\hline Gray fox & 0.16 & 1 & 0.55 & 6 \\
\hline Sylvilagus spp. & 0.31 & 2 & 0.09 & 1 \\
\hline American black bear & 0.16 & 1 & 0.09 & 1 \\
\hline Coyote (Canis latrans) & & & 0.09 & 1 \\
\hline Nutria & & & 0.09 & 1 \\
\hline Striped skunk (Mephitis mephitis) & & & 0.09 & 1 \\
\hline American $\operatorname{mink}^{\mathrm{c}}$ & & & 0.09 & 1 \\
\hline Hispid cotton rat $\left(\right.$ Sigmodon hispidus) ${ }^{\mathrm{c}}$ & & & 0.09 & 1 \\
\hline Unidentified rodent $^{\mathrm{c}^{\mathrm{C}}}$ & & & 0.09 & 1 \\
\hline Subtotal $(n)$ & 5.02 & 32 & 5.15 & 56 \\
\hline Total $(n)$ & 6.59 & 42 & 7.91 & 86 \\
\hline
\end{tabular}

${ }^{a}$ Total length of segments with wildlife underpasses and fencing: 6,375 m.

b Total length of segments without wildlife underpasses and fencing: 10,873 m.

${ }^{c}$ We excluded species from statistical analysis we assumed fit through mesh size $(5 \mathrm{~cm})$ of chain-link fencing. 
Assumptions of normality and equal variances for the mixed-model analysis of variance were met (Shapiro-Wilk $W=0.98, P=0.345$; Levene's $F_{7,47}=1.58, P=0.164$ ). Our analysis of mammal data indicated importance of the covariates segment length $\left(F_{1,50}=6.41, P=0.015\right)$, presence of a forest-agriculture edge $\left(F_{1,50}=14.05, P<\right.$ $0.001)$, and presence of forest on both sides of the highway $\left(F_{1,50}=5.17, P=0.027\right)$. Overall, our model estimated 5.9 $(\mathrm{SE}=2.4)$ mammal mortalities $/ 1 \mathrm{~km}$ of highway during the 13-month sampling period. Compared with other highway segments, each $1 \mathrm{~km}$ of highway with forest-agriculture edges had $1.41(\mathrm{SE}=0.38)$ more mammal mortalities than each $1 \mathrm{~km}$ without forest-agriculture edges. Similarly, for each $1 \mathrm{~km}$ of highway with forest on both sides, 0.82 (SE = 0.36) more mammals were killed by vehicles than for each $1 \mathrm{~km}$ without forest on both sides. Underpass, fenced, and unfenced segments of the highway experienced different frequencies of mammal mortality $\left(F_{2,50}=2.87, P=0.066\right)$; each $1 \mathrm{~km}$ of underpass segments had $1.00(\mathrm{SE}=0.55)$ fewer mortalities than fenced segments (Fisher's least significant difference [LSD] test, $P=0.076)$ but no difference was apparent compared with unfenced segments (0.18 mortalities $/ \mathrm{km}, \mathrm{SE}=0.60$; Fisher's LSD test, $P=$ 0.771). Highway segments with fencing had 0.83 ( $\mathrm{SE}=$ 0.42 ) more mortalities $/ 1 \mathrm{~km}$ than segments without fencing (Fisher's LSD test, $P=0.053$ ). Within fenced segments of highway, frequency of mortalities increased with distance from the nearest wildlife underpass $\left(F_{1,21}=2.26, P=\right.$ $0.035)$, accounting for segment length $\left(F_{1,21}=1.89, P=\right.$ 0.073). Sample sizes for reptiles were too low $(n=25$ mortalities) for a mixed-model analysis of variance.

Given the low ratio of deer mortality to the number of deer crossings based on camera surveys (7:2,258; 0.3\%), we speculated that many deer-vehicle collisions were avoided within our study section of highway. To estimate the level of reduction, we performed an ad hoc analysis and compared the frequency of reported wildlife-vehicle collisions during January 2006-June 2008 (A. C. Braam, NCDOT, unpublished data; approx. 90\% involved white-tailed deer) for our study section of United States Highway 64 (PlymouthCreswell) with sections immediately west (WilliamstonPlymouth) and east (Creswell-Columbia). Landscape patterns were similar for the 2 adjacent sections but no wildlife underpasses were present. We standardized collision frequencies based on the length of each highway section, its average annual daily traffic volume, and length of agriculture-forest edges $/ \mathrm{km}$ of highway (within 1,000 m distance of the highway) as an index of deer habitat quality (see footnote in Table 4 for calculation). Frequencies of standardized wildlife-vehicle collisions were 2.1 times greater for the Williamston-Plymouth section and 2.7 times greater for the Creswell-Columbia section (Table 4). Applying these adjustments to the frequency of wildlifevehicle collision for the Plymouth-Creswell section for the reporting period $(n=10)$, we estimate reductions of 11 (Fisher's exact test, $P=0.035)$ and $17(P=0.004)$ collisions, respectively. Considering that highway segments with underpasses and fencing represented only $17.5 \%$ of the
Plymouth-Creswell section, these estimates likely are conservative.

\section{DISCUSSION}

Based on a meta-analysis of studies in North America, Ford and Fahrig (2007) observed a peaked relationship of body size and frequency of wildlife-vehicle collisions among mammalian species. Those authors suggested that population density and, for mammals $>1.06 \mathrm{~kg}$, mobility are important determining factors. Our findings support this interpretation, with Virginia opossums (Didelphis virginiana) and raccoons (Procyon lotor) alone representing $72 \%$ of all mammalian mortalities. The number of mammal species we detected $(n=12)$ and the number of mortalities/survey effort (46 mammals/1,000 $\mathrm{km}$ surveyed) represented the mid-range of values for studies that Ford and Fahrig (2007) analyzed.

The 2 habitat covariates in our analysis of mammal mortalities suggested that forest-agriculture edges and presence of forest on both sides of the highway were associated with greater frequencies of wildlife-vehicle collisions. Malo et al. (2004) reported similar results for their study in Spain. Inclusion of these variables in the model accounted for some biases due to the original site selection of underpasses, but we probably did not account for all habitat differences. Although the strength of evidence was moderate, we observed biologically meaningful patterns of mammal mortalities among highway segments. Segments at or adjacent to underpasses had fewer mammal mortalities due to vehicle collisions than did fenced segments. However, fenced segments actually experienced a greater frequency of mortality compared with unfenced segments. Moreover, within fenced segments, frequency of wildlife mortalities increased with distance from underpasses. Thus, the effective area of each underpass may be limited to its immediate vicinity (several hundred $\mathrm{m}$ from each entrance). With greater distance from underpasses, probability increases that animals follow fencing away from underpasses and are struck by vehicles when crossing the highway where fencing ends, thus concentrating wildlife-vehicle collisions. Ungulates appear to be particularly vulnerable to this scenario and Clevenger et al. (2001a) suggested this behavior was an important contributor to observed clustering of wildlife-vehicle collisions. Indeed, of 7 deer mortalities we observed, 4 occurred within fenced areas near the edge of fencing. However, deer represented a small proportion of wildlife-vehicle collisions within fenced highway segments (Table 3). Although animals such as opossums and raccoons used underpasses frequently, those animals have smaller home ranges compared with whitetailed deer (Gardner and Sunquist 2003, Gehrt 2003, Miller et al. 2003), and underpasses may have a shorter effective distance (Clevenger et al. 2001b). Those species may initially follow the fence but eventually enter the roadway by climbing over or crawling under the fence, thus remaining vulnerable to collision with vehicles.

Except for 2 amphibian species, nonmammalian mortalities were reptiles. More than half of reptile mortalities
1728

The Journal of Wildlife Management wild-74-08-24.3d $\quad$ 17/9/10 17:42:31
The Journal of Wildlife Management • 74(8)

1728
Cust \# 2009-535R 
Table 4. White-tailed deer vehicle collision data from 3 sections of United States Highway 64 in Martin, Washington, and Tyrrell counties, North Carolina, USA, January 2006-June 2008.

\begin{tabular}{|c|c|c|c|c|c|c|}
\hline $\begin{array}{l}\text { United States Highway } \\
64 \text { section }\end{array}$ & $\begin{array}{c}\text { Section } \\
\text { length }(\mathbf{k m})\end{array}$ & $\begin{array}{c}\text { Reported } \\
\text { wildlife-vehicle } \\
\text { collision frequency }\end{array}$ & $\begin{array}{c}2006 \text { average annual } \\
\text { daily traffic } \\
(\mathrm{AADT})^{\mathrm{b}}\end{array}$ & $\begin{array}{l}\text { Forest-agriculture } \\
\text { edge length }(\mathbf{k m})^{\text {c }}\end{array}$ & $\begin{array}{c}\text { Standardized } \\
\text { wildlife-vehicle } \\
\text { collision frequency }\end{array}$ & Ratio $^{\mathrm{e}}$ \\
\hline Plymouth to Creswell & 36.4 & 10 & 5,268 & 12.435 & $4.194 \times 10^{-6}$ & 1.0 \\
\hline Williamston to Plymouth & 29.0 & 33 & 8,417 & 15.717 & $8.602 \times 10^{-6}$ & 2.1 \\
\hline Creswell to Columbia & 13.5 & 7 & 5,794 & 8.035 & $11.137 \times 10^{-6}$ & 2.7 \\
\hline
\end{tabular}

${ }^{a}$ A. C. Braam, North Carolina Department of Transportation, unpublished data.

b North Carolina Department of Transportation (2006); weighted average based on monitoring distance.

${ }^{c}$ Length of forest-agriculture edge/kilometer of highway. Measurement based on areas within $1 \mathrm{~km}$ of the highway.

${ }^{\mathrm{d}}$ No. of wildlife-vehicle collisions/( $\left.\mathrm{km} \times \mathrm{AADT}\right) /$ forest-agriculture edge length.

e Ratio of standardized wildlife-vehicle collision frequency with study section (Plymouth to Creswell).

involved aquatic turtles, which are vulnerable because of their low recruitment rates and complex movement and habitat ecology, with annual overland movements to visit multiple wetlands (Beaudry et al. 2008). Although our sample size was too low for statistical analysis, our data were indicative that turtles were less vulnerable to road mortality along fenced highway segments (accounting for differences in total length between fenced and unfenced highway segments; Table 3). Wetland and stream habitats associated with the western and central underpasses may have contributed to turtles crossing there. Additionally, Beaudry et al. (2008) suggested that crossing structures may not be effective unless long (hundreds of meters) funneling walls incorporated the full range of potential crossings those authors identified for spotted (Clemmys guttata) and Blanding's turtles (Emydoidea blandingii) in southern Maine, USA. The large span of fencing associated with underpasses $(>800 \mathrm{~m})$ may inadvertently have served this function for turtles in our study, although there were numerous places where turtles could push or dig under the fence.

Clevenger and Waltho (2005) indicated that a variety of attributes contribute to wildlife use of a passageway and that these characteristics are different for each species. Underpasses that were high and wide but short in length promoted use by grizzly bears (Ursus arctos), gray wolves (Canis lupus), elk (Cervus elaphus), and deer (Odocoileus spp.), whereas black bears and pumas ( $P$. concolor) favored less open structures. Land and Lotz (1996) found that river otters (Lontra canadensis), foxes, raccoons, and bobcats (Lynx rufus) used smaller, box-culvert structures in greater proportion than did larger mammals, such as deer and puma, which were more likely to cross at larger underpasses. The 3 underpasses in our study represent a large design and, consequently, white-tailed deer frequently used underpasses. However, the underpass design also provided safe passage for other medium to large mammals native to the project area. We photographed 7 mammal species only during the second study phase $(n=169$ crossings), suggesting underpasses concentrated wildlife use. We note that these findings do not necessarily suggest that connectivity within the project area is greater because of the underpasses. Rather, connectivity remains and is now concentrated along the 3 underpass areas.
Our data indicate that landscape context also played an important role. The central underpass was used most frequently by deer, likely because it provided access to agricultural crops just south of the underpass. Excluding deer, the western underpass received the most frequent use and by the greatest number of species. That underpass contained a small creek and was part of a natural drainage system connected with the Roanoke River northwest of the study area. Black bears primarily used the western and eastern underpasses, which supports findings of telemetry studies by Kindall and van Manen (2007), who showed that these 2 sites provided local and regional habitat linkages. However, black bears did not make exclusive use of underpasses and often crossed the roadway elsewhere, resulting in a high ratio of mortalities to underpass crossings $(2: 17 ; 11.8 \%)$. Besides the 2 bear mortalities documented during our surveys, 6 bear-vehicle collisions were reported in our study section within 16 months after monitoring ended (McCollister 2008; C. Olfenbuttel, NCRWC, personal communication). Seven of those 8 mortalities occurred within unfenced portions of the highway.

Construction of passageways to mitigate vehicle collisions with large mammals can be costly; the 3 underpasses cost approximately US $\$ 3,600,000$, representing approximately $1.85 \%$ of overall costs of the new section of highway (Jones et al. 2010). However, those costs should be weighed against ecological and driver-safety benefits of the underpasses, although such benefits can only partially be expressed in economic terms. The National Highway Traffic Administration estimates that lifetime economic costs of each human traffic fatality are US\$977,000 and average cost for each critically injured person is US $\$ 1,100,000$ (2000 data; Blincoe et al. 2002). Approximately $9 \%$ of those costs are paid with public revenue (Blincoe et al. 2002). Average property damage of a deervehicle collision in Washington County was US\$2,150 (2005-2007 data; A. C. Braam, unpublished data). Given that underpasses and fencing may have reduced the incidence of deer-vehicle collisions in our study area by as much as $58 \%$, the cost-benefit ratio seems favorable over time. For most amphibians, reptiles, and small to medium mammals, our findings support those of other studies that frequent placement of drainage culverts, rather than infrequent, large underpasses, may be a more economical 
approach to mitigating ecological costs of transportation infrastructure (Clevenger et al. 2001b, 2003).

\section{MANAGEMENT IMPLICATIONS}

Deer use of underpasses may be a function of the ease with which deer movements can be guided by fencing. Ironically, this may also contribute to collisions with vehicles when deer attempt to cross the highway where fencing ended. Continuous fencing between underpasses likely would reduce such incidences for deer. At fence ends, directing deer away from the road, as suggested by Clevenger et al. (2001a), may also be effective. However, our data do not indicate that continuous fencing would be effective for many other species, unless they can be prevented from climbing over or pushing underneath chain-link fencing. Barbed-wire outriggers at the top and buried fencing may increase effectiveness (Clevenger et al. 2001a, Ruediger et al. 2006), which could be critical for species for which mortality control is an important goal (e.g., rare, endangered, or game species).

We note the postconstruction study phase started $<1$ year after the highway was opened for traffic. Several researchers have suggested that use of wildlife underpass or drainage culverts may be a learned behavior (Foster and Humphrey 1995, Land and Lotz 1996, Clevenger et al. 2001b). Thus, longer term studies would be important to determine if effectiveness of underpasses increases over time, particularly for bears and other carnivores. Our data could provide a valuable baseline for such studies and we encourage experiments to test different fencing designs and underpass maintenance regimes.

\section{ACKNOWLEDGMENTS}

We thank NCDOT, NCWRC, and Weyerhaeuser Company for funding this study and for their cooperation. We particularly thank M. Jones of the NCWRC for his valuable help throughout the study. J. Nicholson helped collect much of the data while conducting a companion study and L. Thompson and J. Kindall collected preconstruction data. Many others assisted with this study in countless ways, including D. Cox, D. Davis, C. Olfenbuttel, C. Turner, B. White, and T. Wilson of the NCWRC; B. Hulka, D. Miller, and B. Barber of Weyerhaeuser Company; A. Burroughs of the NCDOT; and C. Lucash and F. Mauney of the United States Fish and Wildlife Service. We thank A. Saxton for his statistical expertise and J. D. Clark, D. A. Buehler, L. Muller, J. Peine, J. B. Wilkerson, and C. Snyder for their comments on earlier drafts of this manuscript. Field technicians were J. H. Harrelson, B. Augustine, R. Medford, D. Mauney, J. Hinton, and T. Nicholson. Any use of trade, product, or firm names is for descriptive purposes only and does not imply endorsement by the United States Government.

\section{LITERATURE CITED}

Beaudry, F., P. G. deMaynadier, and M. L. Hunter, Jr. 2008. Identifying road mortality threat at multiple spatial scales for semi-aquatic turtles. Biological Conservation 141:2550-2563.

Blincoe, L., A. Seay, E. Zaloshnja, T. Miller, E. Romano, S. Luchter, and R. Spicer. 2002. The economic impact of motor vehicle crashes, 2000.
U.S. Department of Transportation National Highway Traffic Safety Administration, Washington, D.C., USA.

Clevenger, A. P., B. Chruszcz, and K. E. Gunson. 2001a. Highway mitigation fencing reduces wildlife-vehicle collisions. Wildlife Society Bulletin 29:646-653.

Clevenger, A. P., B. Chruszcz, and K. E. Gunson. 2001b. Drainage culverts as habitat linkages and factors affecting passage by mammals. Journal of Applied Ecology 38:1340-1349.

Clevenger, A. P., B. Chruszcz, and K. E. Gunson. 2003. Spatial patterns and factors influencing small vertebrate fauna road-kill aggregations. Biological Conservation 109:15-26.

Clevenger, A. P., and N. Waltho. 2000. Factors influencing the effectiveness of wildlife underpasses in Banff National Park, Alberta, Canada. Conservation Biology 14:47-56.

Clevenger, A. P., and N. Waltho. 2005. Performance indices to identify attributes of highway crossing structures facilitating movement of large mammals. Biological Conservation 121:453-464.

Conover, M. R., W. C. Pitt, K. K. Kessler, T. J. DuBow, and W. A. Sanborn. 1995. Review of human injuries, illnesses, and economic losses caused by wildlife in the United States. Wildlife Society Bulletin 23:407414.

Cramer, P. C., and J. A. Bissonette. 2006. Wildlife crossings in North America: the state of the science and practice. Pages 442-447 in C. L. Irwin, P. Garrett, and K. P. McDermott, editors. Proceedings of the 2005 international conference on ecology and transportation, San Diego, California. Center for Transportation and the Environment, North Carolina State University, Raleigh, USA.

D’Angelo, G. J., J. G. D’Angelo, G. R. Gallagher, D. A. Osborn, K. V. Miller, and R. J. Warren. 2006. Evaluation of wildlife warning reflectors for altering white-tailed deer behavior along roadways. Wildlife Society Bulletin 34:1175-1183

Evink, G. L. 1996. Florida Department of Transportation initiatives related to wildlife mortality. Pages 278-286 in G. L. Evink, P. Garrett, D. Zeigler, and J. Berry, editors. Trends in addressing transportation related wildlife mortality. Proceedings of the transportation related wildlife mortality seminar. State of Florida Department of Transportation, Tallahassee, USA.

Falk, N. W., H. B. Graves, and E. D. Bellis. 1978. Highway right-of-way fences as deer deterrents. Journal of Wildlife Management 42:646-650.

Feldhamer, G. A., J. E. Gates, D. M. Harman, A. J. Loranger, and K. R. Dixon. 1986. Effects of interstate highway fencing on white-tailed deer activity. Journal of Wildlife Management 50:497-503.

Ford, A. T., and L. Fahrig. 2007. Diet and body size of North American mammal road mortalities. Transportation Research Part D 12:498-505.

Forman, R. T. T., and L. E. Alexander. 1998. Roads and their major ecological effects. Annual Review of Ecology and Systematics 29:207231.

Forman, R. T. T., D. Sperling, J. A. Bissonette, A. P. Clevenger, C. D. Cutshall, V. H. Dale, L. Fahrig, R. France, C. R. Goldman, K. Heanue, J. A. Jones, F. J. Swanson, T. Turrentine, and T. C. Winter. 2003. Road ecology: science and solutions. Island Press, Washington, D.C., USA.

Foster, M. L., and S. R. Humphrey. 1995. Use of highway underpasses by Florida panthers and other wildlife. Wildlife Society Bulletin 23:95-100. Gardner, A. L., and M. E. Sunquist. 2003. Opossum. Pages 3-29 in G. A. Feldhamer, B. C. Thompson, and J. A. Chapman, editors. Wild mammals of North America. John Hopkins University Press, Baltimore, Maryland, USA.

Gehrt, S. D. 2003. Raccoon. Pages 611-634 in G. A. Feldhamer, B. C. Thompson, and J. A. Chapman, editors. Wild mammals of North America. John Hopkins University Press, Baltimore, Maryland, USA.

Groot Bruinderink, G. W. T. A., and E. Hazebroek. 1996. Ungulate traffic collisions in Europe. Conservation Biology 10:1059-1067.

Jones, M. D., F. T. van Manen, T. W. Wilson, and D. R. Cox. 2010. Establishing effective wildlife underpasses on U.S. Highway 64 in North Carolina: integrating management and science objectives. Pages 223-238 in J. P. Beckmann, A. P. Clevenger, M. P. Huijser, and J. A. Hilty, editors. Safe passages: highways, wildlife and habitat connectivity. Island Press, Washington, D.C., USA.

Kindall, J. L., and F. T. van Manen. 2007. Identifying habitat linkages for American black bears in North Carolina, USA. Journal of Wildlife Management 71:487-495.

Kucera, T. E., and R. H. Barrett. 1993. The Trailmaster ${ }^{\circledR}$ Camera system for detecting wildlife. Wildlife Society Bulletin 21:505-508.
1730

The Journal of Wildlife Management wild-74-08-24.3d $\quad$ 17/9/10 17:42:31
The Journal of Wildlife Management • 74(8)

1730
Cust \# 2009-535R 
Land, E. D., and M. Lotz. 1996. Wildlife crossing designs and use by Florida panthers and other wildlife in southwest Florida. Pages 350-355 in G. L. Evink, P. Garrett, D. Zeigler, and J. Berry, editors. Trends in addressing transportation related wildlife mortality. Proceedings of the transportation related wildlife mortality seminar. State of Florida Department of Transportation, Tallahassee, USA.

Ludwig, J., and T. Bremicker. 1983. Evaluation of 2.4-m fences and oneway gates for reducing deer-vehicle collisions in Minnesota. Transportation Research Record 913:19-22.

Malo, J. E., F. Suarez, and A. Diez. 2004. Can we mitigate animal-vehicle accidents using predictive models? Journal of Applied Ecology 41:701-710.

McCollister, M. F. 2008. Impacts of a 4-lane highway on the spatial ecology of American black bears and the effectiveness of wildlife underpasses in eastern North Carolina. Thesis, University of Tennessee, Knoxville, USA.

Miller, K. V., L. I. Muller, and S. Demarais. 2003. White-tailed deer. Pages 906-930 in G. A. Feldhamer, B. C. Thompson, and J. A. Chapman, editors. Wild mammals of North America. John Hopkins University Press, Baltimore, Maryland, USA.

North Carolina Department of Transportation. 2006. Annual average daily traffic (AADT) traffic volume maps. < http://www.ncdot.org/doh/ preconstruct/tpb/traffic_survey/>. Accessed 24 Mar 2009.

Pojar, T. M., R. A. Prosence, D. F. Reed, and T. N. Woodward. 1975. Effectiveness of lighted, animated deer crossing sign. Journal of Wildlife Management 38:87-91.

Reed, D. F., and T. N. Woodward. 1981. Effectiveness of highway lighting in reducing deer-vehicle accidents. Journal of Wildlife Management 45:721-726.

Reed, D. F., T. N. Woodward, and T. M. Pojar. 1975. Behavioral response of mule deer to a highway underpass. Journal of Wildlife Management 39:361-367.
Romin, L. A., and J. A. Bissonette. 1996. Deer-vehicle collisions: status of state monitoring activities and mitigation efforts. Wildlife Society Bulletin 24:276-283.

Ruediger, W. C., K. Wall, and R. Wall. 2006. Effects of highways on elk (Cervus elaphus) habitat in the western United States and proposed mitigation approaches. Pages 269-278 in C. L. Irwin, P. Garrett, and K. P. McDermott, editors. Proceedings of the 2005 international conference on ecology and transportation, San Diego, California. Center for Transportation and the Environment, North Carolina State University, Raleigh, USA.

SAS Institute, Inc. 2005. SAS/Stat users guide, version 9.1. SAS Institute, Cary, North Carolina, USA.

Swann, D. E., C. C. Hass, D. C. Dalton, and S. A. Wolf. 2004. Infraredtriggered cameras for detecting wildlife: an evaluation and review. Wildlife Society Bulletin 32:357-365.

U.S. Census Bureau. 2002. United States census 2000. U.S. Census Bureau, Washington, D.C., USA. < http://www.census.gov/main/www/cen2000. html $>$. Accessed 2 Oct 2008.

Ward, A. L. 1982. Mule deer behavior in relation to fencing and underpasses on Interstate 80 in Wyoming. Transportation Research Record 859:8-13.

Wemmer, C., T. H. Kunz, G. Lundie-Jenkins, and W. J. McShea. 1996. Mammalian sign. Pages 157-176 in D. E. Wilson, F. R. Cole, J. D. Nichols, R. Rudran, and M. S. Foster, editors. Measuring and monitoring biological diversity: standard methods for mammals. Smithsonian Institution Press, Washington, D.C., USA.

Associate Editor: Gehrt. 